\title{
Outcomes of Stemmed versus Un-Stemmed Varus-Valgus Constrained Components in Primary Total Knee Arthroplasty
}

This article was published in the following Dove Press journal: Orthopedic Research and Reviews

\author{
Mina W Morcos $\mathbb{D}^{\prime}$ \\ James L Howard ${ }^{2}$ \\ Brent Lanting ${ }^{2}$ \\ Steven MacDonald (1D ${ }^{2}$ \\ Douglas Naudie $\mathbb{D}^{2}$ \\ Richard McCalden ${ }^{2}$ \\ Edward M Vasarhelyi ${ }^{2}$ \\ 'Division of Orthopaedic Surgery, \\ Department of Surgery, University of \\ Toronto, Toronto, ON, Canada; ${ }^{2}$ Division \\ of Orthopaedic Surgery, Department of \\ Surgery, Western University London \\ Health Sciences Center University \\ Hospital, London, ON, Canada
}

Purpose: The necessity of stemmed components when performing a varus-valgus constrained (VVC) primary total knee arthroplasty (TKA) is unclear. The purpose of this study is to compare the outcomes of primary VVC TKA with and without stems at a minimum of two years.

Methods: Patients in our prospectively collected database with primary VVC TKAs were identified. Patient demographics, prosthesis data, time in vivo, characteristics of revision, and radiographs and PROMs were compared between the stemmed and un-stemmed cohorts.

Results: Sixty-five patients with 69 primary VVC TKAs were identified; 17 were implanted with stems and 52 without stems. Five of the stemmed TKAs $(5 / 17)$ required revision at 15.1 years, while only one of the un-stemmed TKA (1/52) required a revision at 21.6 years $(\mathrm{p}=0.003)$ for aseptic loosening. Of the 5 stemmed TKAs requiring revision, 3 were for aseptic loosening and 2 were for PPJI. The un-stemmed cohort had a significantly higher final total KSS $(\mathrm{p}=0.048)$.

Conclusion: There was no increase in aseptic loosening or revision surgery in patients with non-stemmed primary VVC TKA compared to those with stemmed VVC TKA at mid-term follow-up. Utilizing non-stemmed TKA with VVC in appropriate cases is safe and may reduce cost, shorten operative time, and preserve bone-stock.

Keywords: total knee arthroplasty, knee instability, stemmed implants, constraints

\section{Introduction}

Instability following primary total knee arthroplasty (TKA) is a well-recognized source of early failure. ${ }^{1,2}$ This instability can occur in a number of situations including severe valgus deformities, collateral ligament deficiencies, and irreconcilable flexionextension imbalances. In an effort to combat this instability, a number of authors have reported utilizing varus-valgus constrained (VVC) implants in primary TKA. $^{3-15}$ While these VVC prostheses provide additional coronal plane stability through a larger tibial post and greater post-femoral box conformity, concern remains that this additional level of constraint could result in higher rates of aseptic loosening. ${ }^{16}$

In an attempt to prevent early loosening, some authors have advocated for the use of cemented or press-fit stems to permit force transmission away from the tibial plateau. ${ }^{10,16}$ However, the use of such stems is not completely benign. The addition of these stems can add to overall operating room time, result in higher rates of intraoperative fracture, and potentially contribute to bone loss through stress shielding, without providing a defined advantage over non-stemmed VVC prostheses. ${ }^{17}$
Correspondence: Edward M Vasarhelyi Division of Orthopaedic Surgery, Department of Surgery, Western University London Health Sciences Center University Hospital, 339

Windermere Road, PO Box 5339, London, Ontario N6A 5A5, Canada

$\mathrm{Tel}+$ I $519663-3413$

Fax + I 519 663-3417

Email edward.vasarhelyi@lhsc.on.ca 
While stems have been used historically for VVC prostheses at our institution, we currently do not routinely use stems for primary TKAs when VVC tibial inserts are utilized. The purpose of this study is to compare the outcomes of patients undergoing primary TKA treated with VVC prostheses, with and without stems, at a minimum of two years.

\section{Patients and Methods}

Institutional Review Board approval from the Western University Health Science Research Ethics Board (HSREB) was obtained. Patient consent was not required as the study meets the criteria for secondary use of data set out by the Tri-Council Policy Statement. This study was conducted in accordance with the Declaration of Helsinki and patient confidentiality was maintained during the whole process.

We performed a retrospective review of our prospective Institutional Total Joint Registry for all patients who had undergone implantation of a VVC prosthesis at the time of primary TKA between February 1994 and March 2015. Patients with less than two years of clinical or radiographic follow-up were excluded. Patients were asked to return to clinic if they were at least two years from surgery but did not have available radiographs. Demographic variables including age, gender, body mass index (BMI), type of prosthesis, and reason for utilization of VVC TKA were collected from the electronic medical record for the remaining patients. Radiographs were reviewed to determine whether the VVC prostheses had been implanted with cemented or press-fit stems. Patients were then divided into two groups, those who had received stems and those that had not. These two groups were then compared with respect to a number of outcomes. The primary outcome of interest was revision for aseptic loosening. Secondary outcomes included the Short Form 12 (SF12), the Western Ontario and McMaster Universities Arthritis Index (WOMAC), and the Knee Society Scores (KSS) of the stemmed and un-stemmed cohorts at final follow-up. Incidence of revision for any reason, etiology of revision, and time in vivo were also recorded for any patient who underwent repeat surgery.

The original operative reports were reviewed to determine the reason for the use of a VVC prosthesis. The decision to use a VVC implant as well as whether to use stems or not was made by the treating surgeon, 6 high volume academic arthroplasty surgeons. The type of TKA implanted was also at the treating surgeon's discretion. All patients in the study cohort received one of the following VVC prostheses: Depuy AMK (West Chester, PA), Smith and Nephew Legion (Memphis, TN), Depuy Sigma TC3 (West Chester, PA), Stryker Triathlon TS (Mahwah, NJ), or Zimmer NextGen LCCK (Warsaw, IN). All protheses were cemented and fixed bearing.

Descriptive statistics were calculated for patient demographics, including means, standard deviations and frequencies. Patient-reported outcomes were compared by means of an Independent $T$-Test or nonparametric equivalent for those not meeting distribution requirements. Revision rates for all cause revision and aseptic revisions were compared between stemmed and un-stemmed implants with Fisher Exact Tests. Analyses were performed with IBM Statistical Package for the Social Sciences (version 23, Armonk, NY: IBM Corp). Significance was set at $\mathrm{p}<0.05$.

\section{Results}

One hundred and eight patients who underwent primary TKA utilizing a VVC prosthesis at our institution during the study period were identified. During this time, a total of 13,696 primary TKAs were performed at our institution, for an overall incidence of VVC usage of $0.01 \%$ in primary TKAs. Patients were asked to return to clinic if they were at least two years from surgery but did not have available radiographs. Of the total cohort of 108 patients, 10 patients were excluded because they had less than 2-year follow-up. Twenty-one patients who were deceased, and without any radiographic follow-up in our electronic radiograph system, were also excluded, as we were not able to determine the type of implants that were utilized. An additional 12 patients were excluded because they were unable to be contacted or they refused to return for updated follow-up. This left a total of 65 patients with 69 TKAs to be included as the final patient cohort.

Of the total 69 TKAs, 17 (25\%) were implanted with stems while $52(75 \%)$ were un-stemmed. The mean age of the stemmed group at the time of surgery was 66.7 years (range 41-86) while the mean age of the un-stemmed group was 68.8 years (range $55-86)(\mathrm{p}=0.44)$. In the stemmed group, $14(82 \%)$ of the patients were women while $3(18 \%)$ were men. In the un-stemmed group, 30 (56\%) were women while $22(44 \%)$ were men. The mean BMI in the stemmed group was $30.9 \mathrm{~kg} / \mathrm{m}^{2}$ (range 20.5-46.0), while the mean BMI in the un-stemmed group was 31.2 (range 13.6-45.9) $(\mathrm{p}=0.93)$. The listed reasons for implantation of a VVC prosthesis were "medial laxity" (20/69; 29\%), "antero-posterior 
instability" (9/69; 13\%), "collateral laxity" (9/69; 13\%), "lateral laxity" (7/69; 10\%), "medial collateral ligament partial injury" (7/69; 10\%), "flexion instability" (7/69; 10\%), and in $10(15 \%)$ TKAs the reason was not recorded.

The median time to latest follow-up for the total study cohort was 6.5 years (range 2.07-14.45). Five of the TKAs implanted with stems $(5 / 17 ; 29 \%)$ required a revision at a mean of 15.1 years (range 5.4-20.9), while one of the TKAs implanted without stems $(1 / 52 ; 2 \%)$ required revision at 21.6 years $(\mathrm{p}=0.003)$. In the stemmed group, the most common reason for revision was osteolysis $(3 / 5$; $60 \%$ ), with infection accounting for the other two revisions $(2 / 5 ; 40 \%)$. In the un-stemmed group, osteolysis accounted for the single revision. When infection was excluded, survival in the un-stemmed group was $98.1 \%$ (51/52), while survival in the stemmed group was $82.4 \%$ $(14 / 17)(p=0.047)$ at latest follow-up.

A statistical difference was found between the unstemmed and stemmed groups in their KSS Total scores at latest follow-up (Table 1). Mean KSS Total score in the un-stemmed group was 158.4 while the mean Total score in the stemmed group was $137.0(\mathrm{p}=0.048)$. No statistical difference was seen in the Function subscale between the un-stemmed (68.8) and stemmed (53.3) groups ( $\mathrm{p}=0.068$ ). No statistical difference was seen in the Knee subscale between the un-stemmed (91.9) and stemmed (88.7) groups $(\mathrm{p}=0.264)$.

No statistical difference was observed between the stemmed and un-stemmed groups in either the mental (MCS) or physical (PCS) components of the SF-12 at latest follow-up. The mean MCS for the un-stemmed group was 54.9 while the mean score for the stemmed group was $48.4(\mathrm{p}=0.100)$. The mean PCS for the unstemmed group was 38.9 while the mean score for the stemmed group was $35.3(\mathrm{p}=0.260)$.

No statistical differences were noted between the stemmed and un-stemmed groups in any of the subscale or total WOMAC scores at latest follow-up. The mean Pain score for the un-stemmed group was 80.5 while the mean score for the stemmed group was $72.9(\mathrm{p}=0.311)$. The mean Stiffness score for the un-stemmed group was 73.4 while the mean score for the stemmed group was 67.5 $(\mathrm{p}=0.345)$. The mean Function score for the un-stemmed group was 73.8 while the mean score for the stemmed group was $70.3(\mathrm{p}=0.476)$. The mean total score for the un-stemmed group was 76.9 while the mean score for the stemmed group was $70.5(\mathrm{p}=0.184)$.
Table I Patient-Reported Outcome Scores in the Stemmed and Un-Stemmed Groups

\begin{tabular}{|c|c|c|c|c|}
\hline & Group & $\mathbf{N}$ & Mean & $\mathbf{p}$ \\
\hline \multirow[t]{2}{*}{ [Latest SFI2VI - MCS] } & No Stem & 52 & 54.90 & \multirow[t]{2}{*}{0.100} \\
\hline & Stem & 17 & 48.40 & \\
\hline \multirow[t]{2}{*}{ [Latest SFI2VI - PCS] } & No Stem & 52 & 38.86 & \multirow[t]{2}{*}{0.260} \\
\hline & Stem & 17 & 35.30 & \\
\hline \multirow[t]{2}{*}{ [Latest WOMAC - Pain] } & No Stem & 52 & 80.50 & \multirow[t]{2}{*}{0.311} \\
\hline & Stem & 17 & 72.87 & \\
\hline \multirow[t]{2}{*}{ [Latest WOMAC - Stiffness] } & No Stem & 52 & 73.78 & \multirow[t]{2}{*}{0.345} \\
\hline & Stem & 17 & 67.50 & \\
\hline \multirow[t]{2}{*}{ [Latest WOMAC - Function] } & No Stem & 52 & 73.31 & \multirow[t]{2}{*}{0.476} \\
\hline & Stem & 17 & 69.69 & \\
\hline \multirow[t]{2}{*}{ [Latest WOMAC - Total] } & No Stem & 52 & 73.80 & \multirow[t]{2}{*}{0.184} \\
\hline & Stem & 17 & 70.30 & \\
\hline \multirow[t]{2}{*}{ [Latest KSS - Function] } & No Stem & 52 & 68.80 & \multirow[t]{2}{*}{0.068} \\
\hline & Stem & 17 & 53.30 & \\
\hline \multirow[t]{2}{*}{ [Latest KSS - Knee] } & No Stem & 52 & 91.89 & \multirow[t]{2}{*}{0.264} \\
\hline & Stem & 17 & 88.69 & \\
\hline \multirow[t]{2}{*}{ [Latest KSS - Total] } & No Stem & 52 & 158.40 & \multirow[t]{2}{*}{0.048} \\
\hline & Stem & 17 & 137.00 & \\
\hline
\end{tabular}

Abbreviations: SFI2-MCS, Short Form 12-Mental Components; PCS, physical components; WOMAC, Western Ontario and McMaster Universities Arthritis Index; KSS, Knee Society Score.

\section{Discussion}

We report the outcomes of a cohort of patients who underwent primary total knee replacement with VVC prostheses with and without stems. At a median follow-up of almost 7 years, we did not observe any increase in the rate of aseptic loosening in the patient group who received unstemmed components. The un-stemmed cohort had significantly better KSS Total scores at latest follow-up, with no differences seen between the groups in their SF-12 or WOMAC scores.

A number of authors have reported the outcomes of VVC prostheses implanted during primary total knee arthroplasty. ${ }^{3-8,12-14}$ These studies include an assortment of implant designs and indications. Mid-term results at less than 10 years are available for three of these studies. ${ }^{5,7,14}$ Nam et al reported on the largest cohort of patients of these three studies, $190 \mathrm{VVC}$ knees without stems in 181 
patients at a mean follow-up of 7.3 years. ${ }^{7}$ The authors reported an overall revision rate for aseptic loosening of 2.6\%, with similar KSS, SF-12, and Hospital for Special Surgery (HSS) scores between the VVC patients and a matched cohort of patients who received posterior stabilized (PS) knees. Maynard et al reported on the outcomes of 132 VVC knees with cemented metaphyseal stems from a single manufacturer. ${ }^{5}$ At a mean of 9.2 months, there were no revisions for aseptic loosening with similar WOMAC score improvements as seen in our study. Lastly, Easley et al presented outcomes of $44 \mathrm{VVC}$ knees implanted with short "dangle" stems at a mean of 7.8 years. ${ }^{14}$ No patient required revision for aseptic loosening, and there were no signs of radiographic loosening utilizing the Knee Society radiographic criteria.

Long-term outcomes of stemmed and un-stemmed primary VVC knees, at 10 years and greater, are available in two studies. ${ }^{8,12}$ Lachiewicz et al presented 10-year survival data and clinical results of $54 \mathrm{VVC}$ prostheses implanted without the routine use of stems. ${ }^{12}$ The authors reported an aseptic loosening rate of $3.7 \%(2 / 54)$, with both TKAs loosening within 3 years. Cholewinski et al examined the outcomes of 43 stemmed VVC TKAs at a mean of 12.7 years follow-up. ${ }^{8}$ Similar improvements in patient outcome scores were noted. No cases of aseptic loosening were seen at final follow-up.

One of the strengths of our study is the use of prospectively collected data retrieved from our institutional total joint registry. At our institution, outcome scores are collected at routine follow-ups, permitting the use of prospectively collected information for outcome studies. Furthermore, as our center serves as the only tertiary-care arthroplasty center in our region, we feel that our rate of revision is accurate as it is unlikely that patients would go elsewhere for revision. The weaknesses include the retrospective design of the study as well as the somewhat limited number of patients within the study. A further weakness is the fact that the decision to use a stem or not was at the discretion of the surgeon. Therefore, it is possible these two cohorts of patients were significantly different with respect to their clinical status (ie, bone defects, degree of ligamentous instability, previous number of operations, etc.), which could have influenced the clinical findings of our study. This does indicate, however, that when appropriate bony support is available, VVC TKA can be used safely with primary TKA components without the need for stems. This may have benefits of cost savings, when compared to revision components, a shorter operative time, and preservation of bone stock for possible revision surgery in the future.

\section{Conclusion}

We report the outcomes of patients from our institution who underwent primary total knee arthroplasty with varusvalgus constrained prostheses both with and without stems. Our outcomes differ from much of the existing mid- and long-term literature as we directly compare stemmed and un-stemmed groups, without an increase in aseptic loosening in the un-stemmed group. At mid-term follow-up, our results suggest that patients can receive unstemmed VVC prostheses, when required, at the time of primary TKA without concern for early aseptic loosening.

\section{Disclosure}

Dr James L Howard reports personal fees/grants for institutional research supports from Stryker, DePuy, Smith and Nephew, and Intellijoint, outside the submitted work. Dr Brent Lanting reports grants and personal fees for institutional supports from Stryker, DePuy, Smith and Nephew, and Zimmer, outside the submitted work. Dr Steven MacDonald reports personal fees for research support IP royalties and consulting from DePuy, A Johnson \& Johnson Company, Smith \& Nephew, and Stryker, receives stock options from Hip Innovation Technology, JointVue, Curvafix, Parvizi Surgical Innovation, and Orthophor, outside the submitted work. Dr Douglas Naudie reports personal fees from Smith and Nephew, outside the submitted work; and Institutional and educational support was received from Smith and Nephew, Depuy, and Stryker. Dr Edward M Vasarhelyi reports grants, personal fees for institutional and research support from DePuy, Stryker, Smith and Nephew, and Hip Innovation Technology, outside the submitted work. The authors report no other conflicts of interest in this work.

\section{References}

1. Fehring TK, Odum S, Griffin WL, Mason JB, Nadaud M. Early failures in total knee arthroplasty. Clin Orthop. 2001;392:315-318. doi:10.1097/00003086-200111000-00041

2. Sharkey PF, Hozack WJ, Rothman RH, Shastri S, Jacoby SM. Insall award paper: why are total knee arthroplasties failing today? Clin Orthop. 2002;404:7-13. doi:10.1097/00003086-200211000-00003

3. Deshmukh AJ, Rathod PA, Moses MJ, Snir N, Marwin SE, Dayan AJ. Does a non-stemmed constrained condylar prosthesis predispose to early failure of primary total knee arthroplasty? Knee Surg Sport Traumatol Arthrosc. 2015. 
4. Lachiewicz PF, Soileau ES. Results of a second-generation constrained condylar prosthesis in primary total knee arthroplasty. J Arthroplasty. 2011;26(8):1228-1231. doi:10.1016/j.arth.2011.05.010

5. Maynard LM, Sauber TJ, Kostopoulos VK, Lavigne GS, Sewecke JJ, Sotereanos NG. Survival of primary condylar-constrained total knee arthroplasty at a minimum of 7 years. $J$ Arthroplasty. 2014;29:1197-1201. doi:10.1016/j.arth.2013.11.018

6. Anderson JA, Baldini A, MacDonald JH, Tomek I, Pellici PM, Sculco TP. Constrained condylar knee without stem extensions for difficult primary total knee arthroplasty. $J$ Knee Surg. 2007;20:195-198. doi:10.1055/s-0030-1248042

7. Nam D, Umunna BPN, Cross MB, Reinhardt KR, Duggal S, Cornell CN. Clinical results and failure mechanisms of a nonmodular constrained knee without stem extensions. J HSS. 2012;8:96-102. doi:10.1007/s11420-012-9277-9

8. Cholewinski P, Putman S, Vasseur L, et al. Long-term outcomes of primary constrained condylar knee arthroplasty. Orthop Traumatol Surg Res. 2015;101:449-454.

9. Camera A, Biggi S, Cattaneo G, Brusaferri G. Ten-year results of primary and revision condylar-constrained total knee arthroplasty in patients with severe coronal plane instability. Open Orthop J. 2015;9:379-389. doi:10.2174/1874325001509010379

10. Macdessi SJ, Rich DS, Buly RL, Walcott-Sapp S, Westrich G. Early femoral component loosening of constrained condylar primary total knee arthroplasties inserted without stems. J Orthop. 2008;5(1):e20.
11. Hartford JM, Goodman SB, Schurman DJ, Knoblick G. Complex primary and revision total knee arthroplasty using the condylar constrained prosthesis: an average 5-year follow-up. J Arthroplasty. 1998;13(4):380-387. doi:10.1016/S0883-5403(98)90002-X

12. Lachiewicz PF, Soileau ES. Ten-year survival and clinical results of constrained components in primary total knee arthroplasty. J Arthroplasty. 2006;21(6):803-808. doi:10.1016/j.arth.2005.09.008

13. Anderson JA, Baldini A, MacDonald JH, Pellicci PM, Sculco TP. Primary constrained condylar knee arthroplasty without stem extensions for the valgus knee. Clin Orthop Relat Res. 2006;442:199-203. doi:10.1097/01.blo.0000185675.99696.29

14. Easley ME, Insall JN, Scuderi GR, Bullek DD. Primary constrained condylar knee arthroplasty for the arthritic valgus knee. Clin Orthop Relat Res. 2000;380:58-64. doi:10.1097/00003086-20001100000008

15. Weiss RJ, Thorsell M, Stark A, Nyvang J, Hedstrom M. 2- to 9-yer outcome of stemmed total knee arthroplasty: similar failure rates in patients when used primary or as a revision. Acta Orthop. 2014;85 (6):609-613. doi:10.3109/17453674.2014.962411

16. Morgan H, Battista V, Leopold SS. Constraint in primary total knee arthroplasty. J Am Acad Orthop Surg. 2005;13:515-524. doi:10.5435/ 00124635-200512000-00004

17. Delasotta LA, Orozco F, Miller AG, Post Z, Ong A. Distal femoral fracture during primary total knee arthroplasty. J Orthop Surg. 2015;23(2):202-204. doi:10.1177/230949901502300218
Orthopedic Research and Reviews

\section{Publish your work in this journal}

Orthopedic Research and Reviews is an international, peer-reviewed, open access journal that focusing on the patho-physiology of the musculoskeletal system, trauma, surgery and other corrective interventions to restore mobility and function. Advances in new technologies, materials, techniques and pharmacological agents are particularly welcome. The manuscript management system is completely online and includes a very quick and fair peer-review system, which is all easy to use. Visit http://www.dovepress.com/testimonials.php to read real quotes from published authors. 